\title{
Coal-Tar-Based Pavement Sealcoat-Potential Concerns for Human Health and Aquatic Life
}

Sealcoat is the black, viscous liquid sprayed or painted on many asphalt parking lots, driveways, and playgrounds to protect and enhance the appearance of the underlying asphalt. Studies by the U.S. Geological Survey (USGS), academic institutions, and State and local agencies have identified coal-tar-based pavement sealcoat as a major source of polycyclic aromatic hydrocarbon (PAH) contamination in urban and suburban areas and a potential concern for human health and aquatic life. ${ }^{1}$

\section{Key Findings:}

Human Health Concerns - As coal-tar-based sealcoat ages, it wears into small particles with high levels of PAHs that can be tracked into homes and incorporated into house dust. For people who live adjacent to coaltar-sealcoated pavement, ingestion of PAH-contaminated house dust and soil results in an elevated potential cancer risk, particularly for young children. Exposure to PAHs, especially early in childhood, has been linked by health professionals to an increased risk of lung, skin, bladder, and respiratory cancers. ${ }^{2}$

Aquatic Life Concerns - Runoff from coal-tar-sealcoated pavement, even runoff collected more than 3 months after sealcoat application, is acutely toxic to fathead minnows and water fleas, two species commonly used to assess toxicity to aquatic life. Exposure to even highly diluted runoff from coal-tar-sealcoated pavement can cause DNA damage and impair DNA repair. These findings demonstrate that coal-tar-sealcoat runoff can remain a risk to aquatic life for months after application.

Coal-tar-sealcoat, which contains elevated levels of PAHs, is commonly applied to parking lots, driveways, and some recreational areas across the central and eastern parts of the United States. Friction from vehicle tires abrades sealcoat into small particles that can be tracked indoors or washed down storm drains and into streams, potentially harming human and aquatic life.
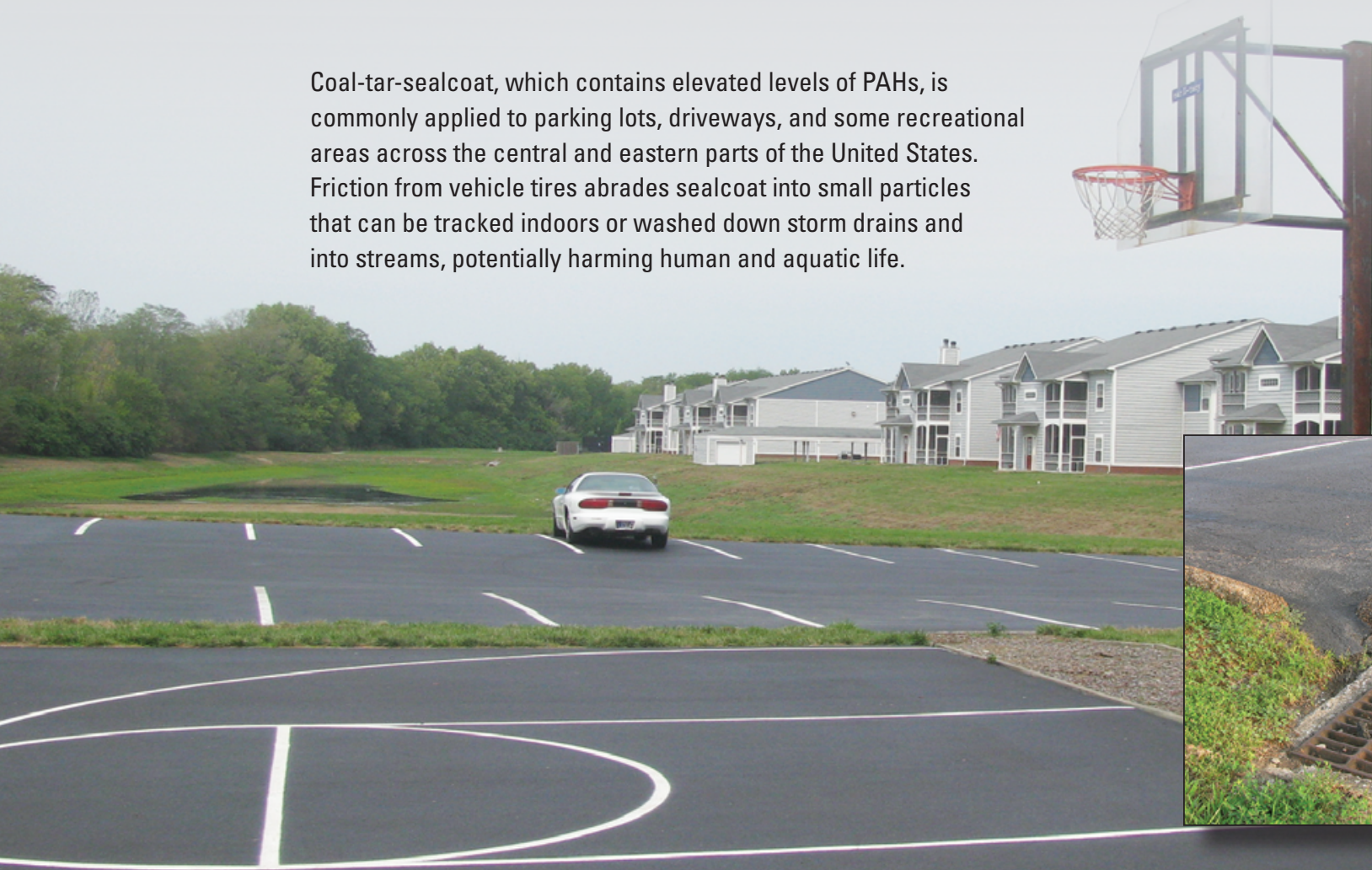

into streams, potentially harming human and aquatic life. 


\section{As Sealcoat Wears Off, Where Does It Go?}

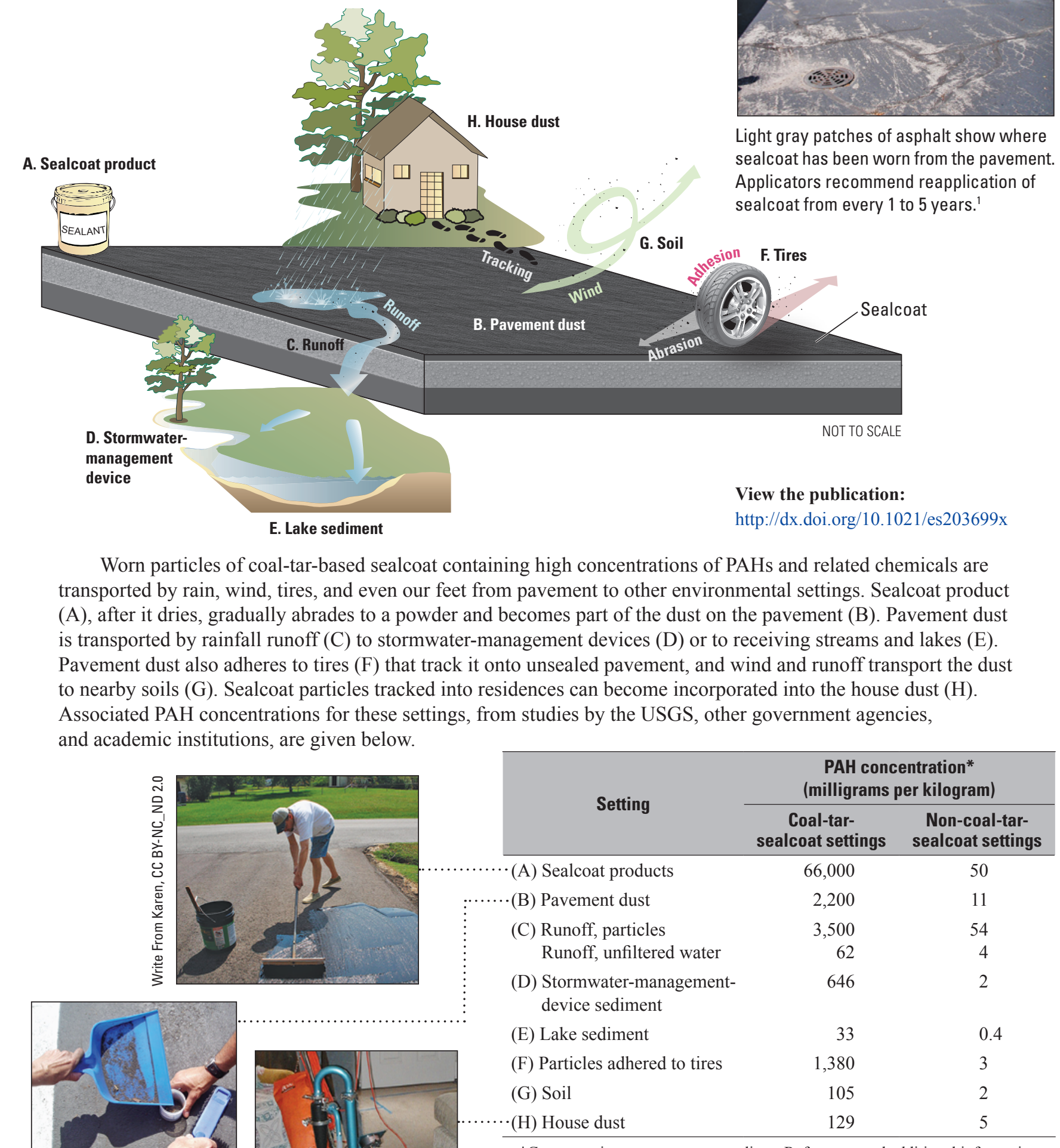

(H) House dust

129

*Concentrations are means or medians. References and additional information are provided in Mahler and others (2012). ${ }^{1}$ 


\section{PAH Levels in Asphalt-Based and Coal-Tar-Based Sealcoat}

Pavement sealcoat is a commercial product that is applied to many asphalt parking lots, driveways, and playgrounds in North America in an effort to protect and beautify the underlying asphalt. It rarely is used on public roads.

Most sealcoat products are either coal-tar or asphalt emulsion, although some alternative products now are available. ${ }^{3}$ Coal tar and coal-tar pitch have extremely high concentrations of PAHs as do coal-tar-based sealcoat products, which typically are 20-35 percent coal tar or coal-tar pitch. Asphalt and asphalt-based sealcoat products have much lower concentrations of PAHs.

For historical and economic reasons, use of asphalt-based sealcoat in the United States is more common west of the Continental Divide and use of coal-tarbased sealcoat is more common east of the Continental Divide, except in States, counties, and municipalities where use of coal-tar-based sealcoat is prohibited. ${ }^{3}$

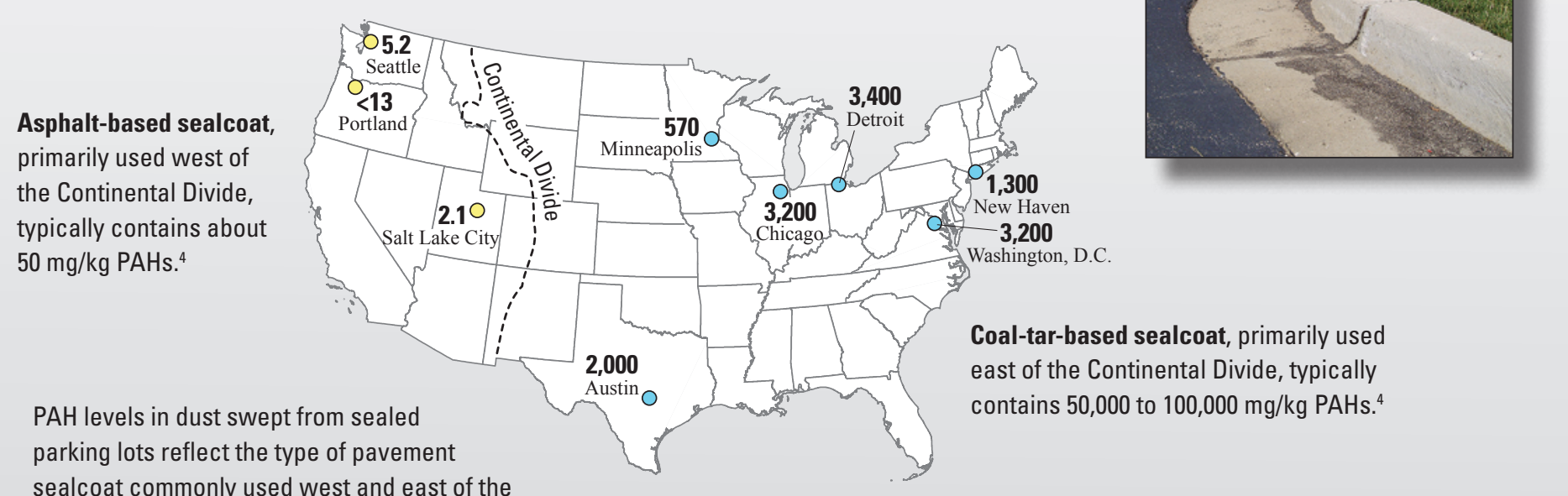
sealcoat commonly used west and east of the

Continental Divide.' Concentrations, in units of milligrams per kilogram $(\mathrm{mg} / \mathrm{kg}$ ), also referred to as "parts per million" (ppm), shown here are for the sum of the 16 PAHs listed by the U.S. Environmental Protection Agency as Priority Pollutants. Concentrations are for composite samples from multiple parking lots or a median of several individual samples. ${ }^{5}$

Polycyclic aromatic hydrocarbons (PAHs) are a group of chemicals created by heating or burning material that contains carbon. The many sources of PAHs to the urban environment span a wide range of PAH concentrations and include asphalt $(2-9 \mathrm{mg} / \mathrm{kg})$, tire particles $(84 \mathrm{mg} / \mathrm{kg})$, used motor oil $(730 \mathrm{mg} / \mathrm{kg})$, and coal-tar-based sealcoat $(34,000-202,000 \mathrm{mg} / \mathrm{kg}){ }^{6}$ PAHs are an environmental concern because many cause cancer, mutations, birth defects, or death in fish, wildlife, and invertebrates. ${ }^{7}$ Exposure to sunlight greatly intensifies the adverse effects of several PAHs. The U.S. Environmental Protection Agency (EPA) has classified seven PAHs as probable human carcinogens (Class B2) and 16 PAHs as Priority Pollutants. Environmental and health effects depend on which PAHs are present and their concentrations.

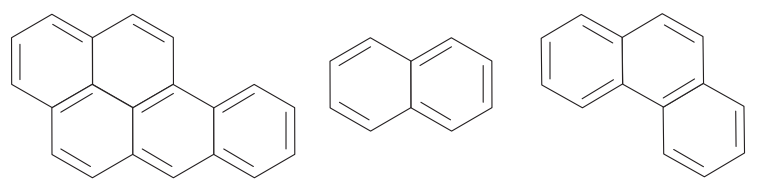

PAHs are made up of various arrangements of benzene rings. PAHs commonly occur in the environment as mixtures, which typically include at least some of the PAHs that are classified as probable human carcinogens.
Coal tar is a byproduct of the coking, liquefaction, or gasification of coal and is a complex mixture composed primarily of aromatic hydrocarbons. Coal-tar pitch is the residue that remains after the distillation of coal tar; it is a complex mixture of high molecular weight aromatic hydrocarbons and black carbon solids. The primary use of coal-tar pitch is in electrode manufacturing for the aluminum industry. ${ }^{8}$ Coal-tar emulsion pavement sealants contain either crude coal tar (Chemical Abstracts Service [CAS] Registry Number 8007-45-2) or coal-tar pitch (CAS Registry Number 65996-93-2). Coal tar and coal-tar pitch are known human carcinogens. ${ }^{9}$

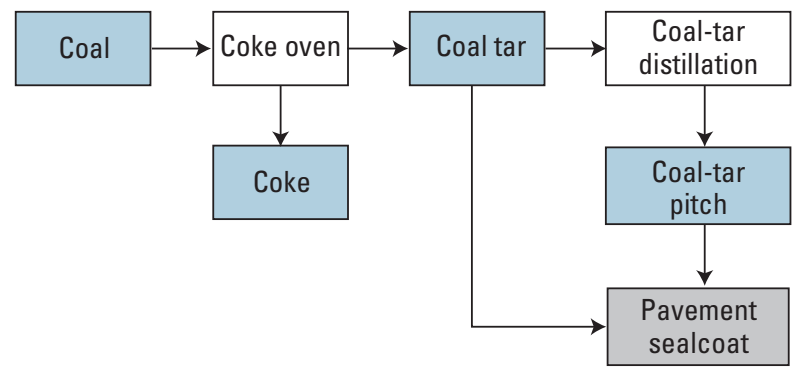




\section{Potential Risks to Human Health}

\section{PAHs from coal-tar-based sealcoat contaminate house dust ${ }^{10}$}

In a study of 23 ground-floor apartments in Austin, Texas, PAH levels in house dust in apartments with parking lots sealed with a coal-tar-based product were 25 times higher than in house dust in apartments with parking lots with other surface types (concrete, unsealed asphalt, and asphalt-based sealcoat). No relation was found between PAHs in house dust and other

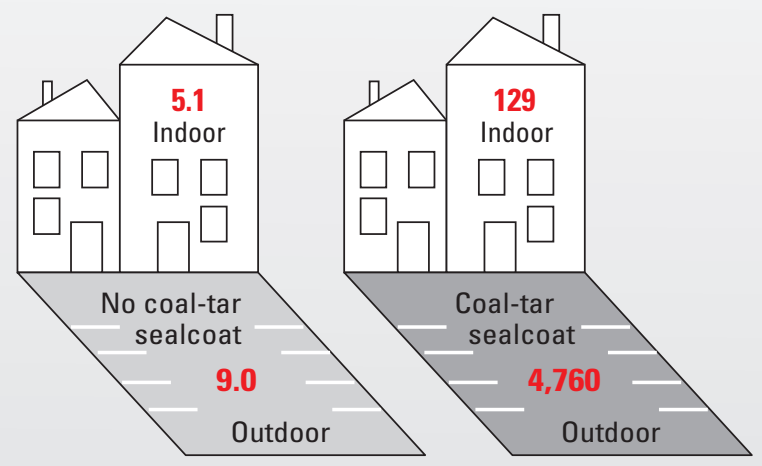

PAH-contaminated dust on coal-tar-sealcoated pavement (right) is tracked indoors. ${ }^{10}$ Concentrations shown are median values for the sum of the 16 Priority Pollutant PAHs, in units of milligrams per kilogram, in house dust and parking lot dust.

View the publication:

http://pubs.acs.org/doi/pdf/10.1021/es902533r possible indoor PAH sources such as tobacco smoking and fireplace use.

House dust is an important pathway for human exposure to many contaminants, including PAHs. This is particularly true for small children, who spend time on the floor and put their hands and objects into their mouths.

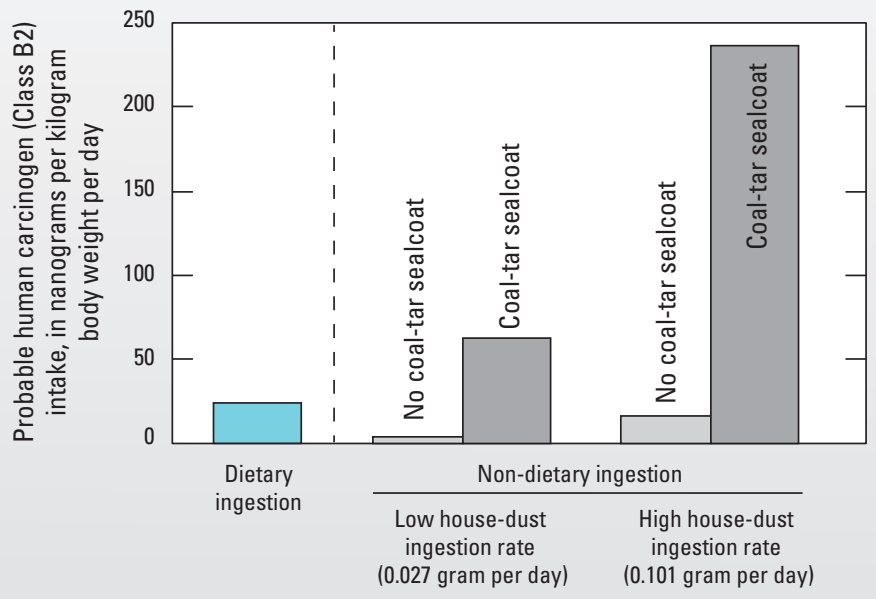

The preschooler living in a residence adjacent to coal-tar-sealed pavement who has relatively low hand-to-mouth activity consumes about 2.5 times more PAHs from house dust than from their diet. ${ }^{11}$ For the more active preschooler, whose hand-to-mouth activity is higher, the PAH intake from house dust is nearly 10 times more than the PAH intake from their diet.

\section{Living adjacent to coal-tar-sealed pavement increases cancer risk ${ }^{12}$}

The USGS partnered with a human-health-risk analyst to estimate the excess lifetime cancer risk associated with the ingestion of house dust and soil for people living adjacent to parking lots with and without coal-tarbased sealcoat. Excess cancer risk is the extra risk of developing cancer caused by exposure to a toxic substance. The excess cancer risk for people living adjacent to coal-tar-sealcoated pavement (1.1 cancer incidences for every 10,000 individuals exposed) was 38 times higher, on average (central tendency), than for people living adjacent to unsealed pavement. The central tendency excess cancer risk estimated for people living adjacent to coal-tar-sealcoated pavement exceeds the threshold generally considered by the EPA as making remediation advisable.

The assessment used measured concentrations of the B2 PAHs in house dust and soils adjacent to coal-tar-sealed pavement (adjusted for relative potency to the PAH benzo[ $[a]$ pyrene), established house dust and soil ingestion rates, and the EPA-established slope factor to estimate the excess cancer risk. Much of the estimated excess risk comes from exposures to PAHs in early childhood (that is, $0-6$ years of age). The study did not consider the excess cancer risk associated with exposure to the sealcoated pavement itself, which has PAH concentrations 10 or more times greater than in adjacent residence house dust or soils. ${ }^{5,10}$

View the publication:

Children ingest

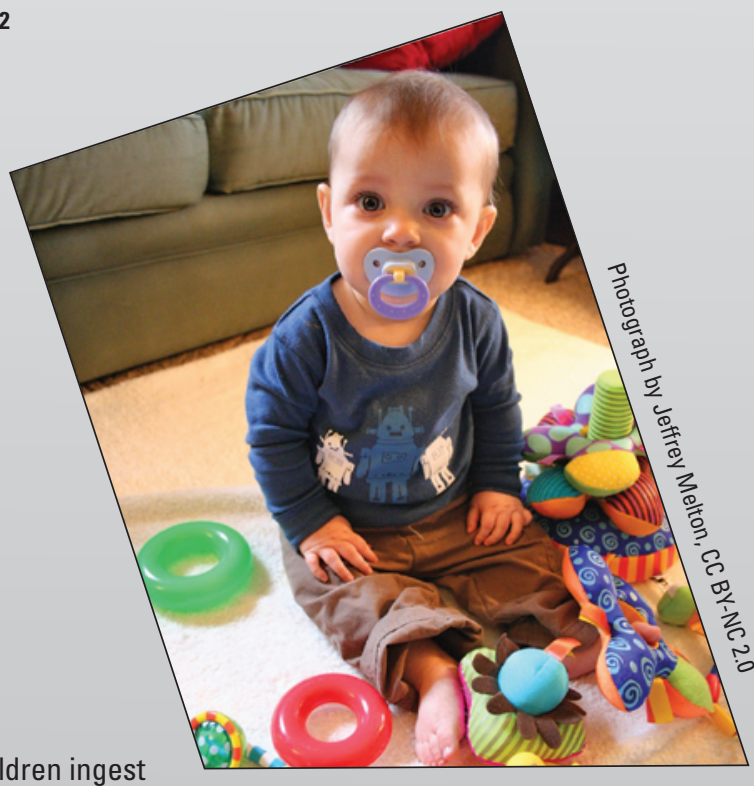

house dust and soil when they put their hands or objects into their mouth. Much of the estimated excess cancer risk associated with the ingestion of PAH-contaminated soil and house dust is incurred during early childhood. 


\section{Potential Risks to Aquatic Life}

\section{Runoff from coal-tar-sealcoated pavement is acutely toxic to aquatic biota ${ }^{13}$}

Exposure to runoff from coal-tar-sealed pavement collected as much as 42 days after sealcoat application resulted in 100 percent mortality to two commonly tested laboratory organisms: day-old fathead minnows (Pimephales promelas) and water fleas (Ceriodaphnia dubia). In contrast, minnows and water fleas exposed to runoff from unsealed pavement experienced no more than 10 percent mortality. When the minnows and water fleas were also exposed to simulated sunlight, which intensifies the toxicity of some PAHs, runoff collected 111 days (more than 3 months) after sealcoat application caused 100 percent mortality to both species, and caused 100 percent mortality to water fleas even when diluted to 10 percent of its original strength.

The USGS collected samples of runoff from 5 hours to 111 days following sealcoat application to pavement by a professional applicator. Total PAH concentrations varied relatively little, as rapid decreases in concentrations of low molecular weight and nitrogen-substituted PAHs were offset by increases in high molecular weight PAHs. ${ }^{14}$ These results demonstrate that runoff from coal-tar-sealcoated pavement continues to contain elevated concentrations of PAHs and related compounds long after a 24-hour curing time.

A subsequent study by researchers at the National Oceanic and Atmospheric Administration (NOAA) and the U.S. Fish and Wildlife Service found that coal-tar-sealcoat runoff is acutely lethal to juvenile coho salmon (Oncorhynchus kisutch) and causes a wide spectrum of abnormalities to zebrafish (Danio rerio) embryos. ${ }^{15}$ They also reported that filtration of the runoff through a biorention system substantially reduced toxicity.
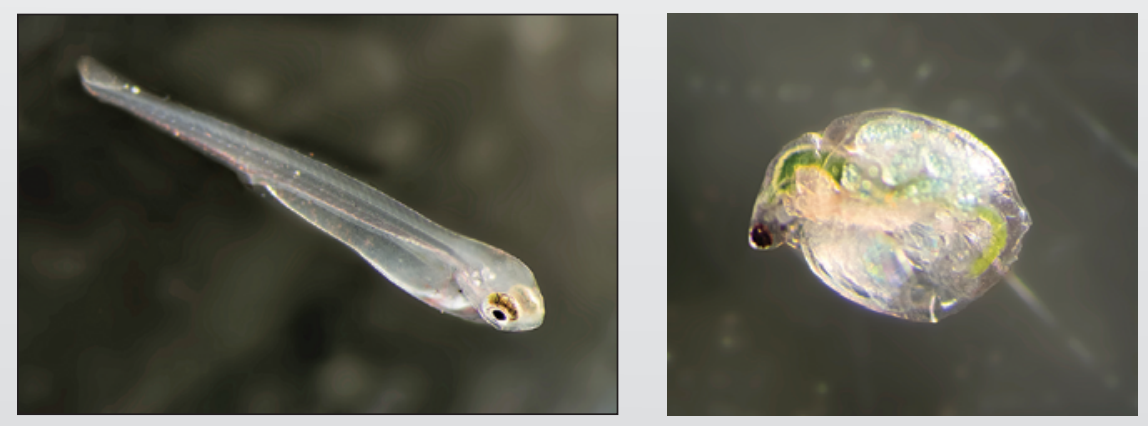

Runoff from coal-tar-sealcoated pavement is acutely toxic to fathead minnows (Pimephales promelas; left) and water fleas (Ceriodaphnia dubia; right).

View the publication:

http://pubs.acs.org/doi/abs/10.1021/acs.est.5b00933

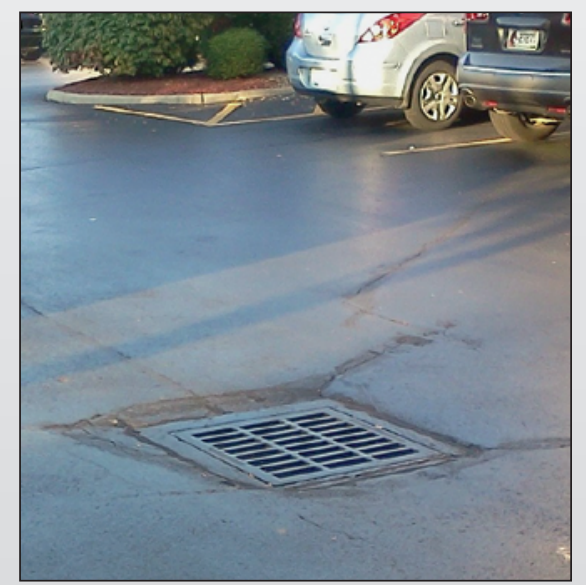

Runoff from coal-tar-sealcoated pavement goes down storm drains to receiving water bodies. The runoff contains high concentrations of PAHs and related chemicals that can harm aquatic life. ${ }^{16}$

\section{Runoff from coal-tar-sealcoated pavement damages DNA and impairs DNA repair ${ }^{17}$}

Simultaneous exposure to runoff from coal-tar-sealed pavement and simulated sunlight damaged DNA in rainbow trout liver cells, even when the runoff was diluted to 1 percent of its initial concentration. The cells were from a cell line developed to assess the effects of PAHs on DNA. The test assessed two types of DNA damage: strand breaks and alkylated bases.

Although cells can repair some DNA damage, a second experiment demonstrated that cells exposed to the coal-tar-sealcoat runoff had an impaired capacity to perform at least one type of DNA repair. The combination of DNA damage and impaired repair capacity intensifies the potential for long-term damage to cell health. DNA damage has many possible consequences, including aging, cell death, and mutations. Mutations can affect the function of genes and can potentially lead to cancer.

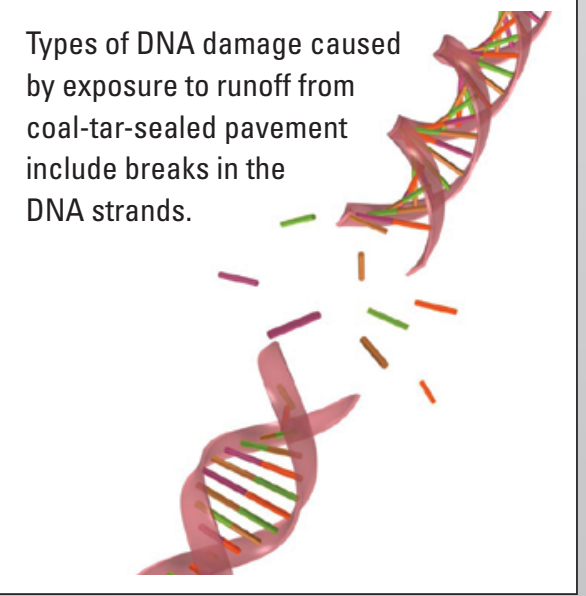




\section{Air-Quality Concerns ${ }^{18,19}$}

Although unseen, releases of PAHs to the atmosphere (volatilization) from freshly coal-tar-sealed pavement are tens of thousands of times higher than from unsealed pavement. Volatilization is a potential human-health concern because inhalation is an important pathway for human exposure to PAHs. Although volatilization decreases rapidly over the weeks following application, it nonetheless continues long after application-PAH releases to the atmosphere from parking lots sealed from 3 to 8 years prior to sampling were on average 60 times higher than PAH releases from unsealed pavement.

Nationwide, the combined PAH releases each year from newly applied coal-tar-based sealcoat are estimated to exceed annual vehicle emissions of PAHs. ${ }^{18} \mathrm{PAH}$ releases shown here are in units of micrograms per meter squared per hour $\left(\mu \mathrm{g} / \mathrm{m}^{2}-\mathrm{h}\right)$.

\section{References Cited}

1. Mahler, B.J., Van Metre, P.C., Crane, J.L., Watts, A.W., Scoggins, M., and Williams, E.S., 2012, Coal-tar-based pavement sealcoat and PAHsImplications for the environment, human health, and stormwater management: Environmental Science and Technology, v. 56, p. 3039-3045.

2. Agency for Toxic Substances and Disease Registry, 1995, Toxicological profile for polycyclic aromatic hydrocarbons: Atlanta, Ga., U.S. Department of Health and Human Services, Public Health Service, accessed November 16, 2015, at http://www.atsdr.cdc.gov/toxprofiles/ tp.asp?id=122\&tid=25.

3. Minnesota Pollution Control Agency, 2014, Choosing alternatives to coal tar-based pavement sealcoats, accessed November 16, 2015, at https://www. pca.state.mn.us/water/stormwater-great-lakes-coal-tar-sealcoat-pah-reduction.

4. City of Austin, 2005, PAHs in Austin, Texas sediments and coal-tar-based pavement sealants polycyclic aromatic hydrocarbons: City of Austin Watershed Protection and Development Review Department, 55 p., accessed January 20, 2016, at http://www.austintexas.gov/department/coal-tar.

5. Van Metre, P.C., Mahler, B.J., and Wilson, J.T., 2009, PAHs underfootContaminated dust from coal-tar sealcoated pavement is widespread in the United States: Environmental Science and Technology v. 43, p. 20-25, accessed January 20, 2016, at http://pubs.acs.org/doi/abs/10.1021/es802119h.

6. Mahler, B.J., Van Metre, P.C., Bashara, T.J., Wilson, J.T., and Johns, D.A., 2005, Parking lot sealcoat-An unrecognized source of urban polycyclic aromatic hydrocarbons: Environmental Science and Technology, v. 39, p. 5560-5566, accessed January 20, 2016, at http://pubs.acs.org/doi/abs/ 10.1021/es0501565.

7. Eisler, R., 1987, Polycyclic aromatic hydrocarbon hazards to fish, wildlife, and invertebrates - A synoptic review: U.S. Fish and Wildlife Service Biological Report 85(1.11), accessed January 20, 2016, at http://www.pwrc.usgs.gov/ oilinla/pdfs/CHR_11_PAHs.pdf.

8. International Agency for Research on Cancer, 2010, Some non-heterocyclic polycyclic aromatic hydrocarbons and some related exposures: IARC Monographs on the Evaluation of Carcinogenic Risks to Humans, v. 92 [working group met in Lyon, France, Oct. 11-18, 2005], accessed January 20, 2016, at http://monographs.iarc.fr/ENG/Monographs/vo192/mono92.pdf.

9. National Toxicology Program, 2014, Report on carcinogens (13th ed.): Research Triangle Park, N.C., U.S. Department of Health and Human Services, Public Health Service, accessed January 20, 2016, at http://ntp.niehs.nih.gov/pubhealth/roc/roc13/.

10. Mahler, B.J., Van Metre, P.C., Wilson, J.T., Musgrove, M., Burbank, T.L., Ennis, T.E., and Bashara, T.J., 2010, Coal-tar-based parking lot sealcoatAn unrecognized source of PAH to settled house dust: Environmental Science and Technology, v. 44, p. 894-900.

11. Williams, E.S., Mahler, B.J., and Van Metre, P.C., 2012, Coal-tar pavement sealants might significantly increase children's PAH exposures: Environmental Pollution, v. 164, p. 40-41, accessed January 20, 2016, at http://www.sciencedirect.com/science/article/pii/S0269749112000279.

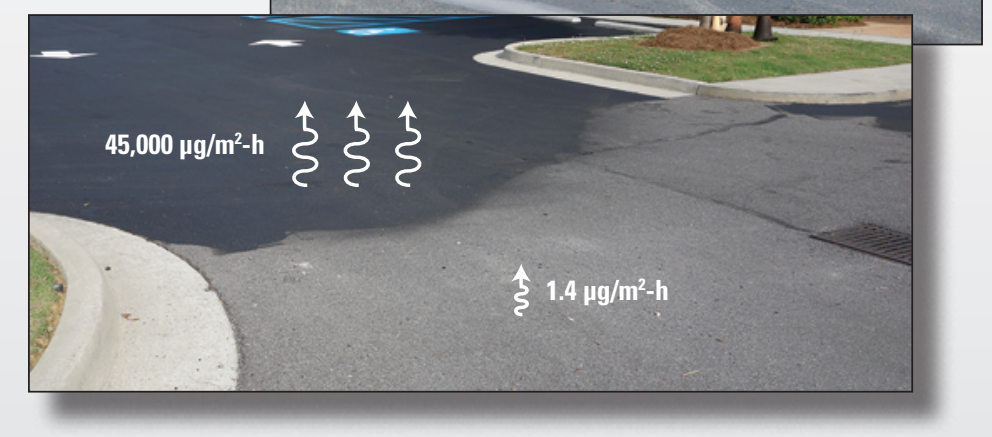

12. Williams, E.S., Mahler, B.J., and Van Metre, P.C., 2013, Cancer risk from incidental ingestion exposures to PAHs associated with coal-tar-sealed pavement: Environmental Science and Technology, v. 47, p. 1101-1109.

13. Mahler, B.J., Ingersoll, C.G., Van Metre, P.C., Kunz, J.L., and Little, E.E., 2015, Acute toxicity of runoff from sealcoated pavement to Ceriodaphnia dubia and Pimephales promelas: Environmental Science and Technology, v. 49, p. 5060-5069.

14. Mahler, B.J., Van Metre, P.C., and Foreman, W.T., 2014, Concentrations of polycyclic aromatic hydrocarbons (PAHs) and azaarenes in runoff from coal-tar- and asphalt-sealcoated pavement: Environmental Pollution, v. 188, p. 81-87, accessed January 20, 2016, at http://www.sciencedirect.com/ science/article/pii/S0269749114000141.

15. McIntyre, J.K., Edmunds, R.C., Anulacion, B.F., Davis, J.W., Incardona, J.P., Stark, J.D., and Scholz, N.L., 2015, Severe coal tar sealcoat runoff toxicity to fish is prevented by bioretention filtration: Environmental Science and Technology, v. 50, p. 1570-1578, accessed January 20, 2016, at http://pubs.acs.org/doi/abs/10.1021/acs.est.5b04928.

16. Douben, P.E.T., 2003, PAHs-An ecotoxicological perspective: West Sussex, England, John Wiley \& Sons Ltd., 392 p.

17. Kienzler, A., Mahler, B.J., Van Metre, P.C., Schweigert, N., Devaux, A., and Bony, S., 2015, Exposure to runoff from coal-tar-sealed pavement induces genotoxicity and impairment of DNA repair capacity in the RTL-W1 fish liver cell line: Science of the Total Environment, v. 520, p. 73-80, accessed January 20, 2016, at http://www.sciencedirect.com/science/article/pii/ S0048969715002703.

18. Van Metre, P.C., Majewski, M.S., Mahler, B.J., Foreman, W.T., Braun, C.L., Wilson, J.T., and Burbank, T., 2012, PAH volatilization following application of coal-tar-based pavement sealant: Atmospheric Environment, v. 51, p. 108-115, accessed January 20, 2016, at http://www.sciencedirect.com/ science/article/pii/S135223101200057X.

19. Van Metre, P.C., Majewski, M.S., Mahler, B.J., Foreman, W.T., Braun, C.L., Wilson, J.T., and Burbank, T., 2012, Volatilization of polycyclic aromatic hydrocarbons from coal-tar-sealed pavement: Chemosphere, v. 88, p. 1-7, accessed January 20, 2016, at http://dx.doi.org/10.1016/j.chemosphere. 2011.12.072.

By Barbara J. Mahler,* Michael D. Woodside, and Peter C. Van Metre

\section{For more information}

Access publications and learn more about PAHs and coal-tar-based pavement sealcoat at http://tx.usgs.gov/sealcoat.html. *bjmahler@usgs.gov
ISSN 2327-6916 (print) ISSN 2327-6932 (online) http://dx.doi.org/10.3133/fs20163017 